INTERNATIONAL DESIGN CONFERENCE - DESIGN 2018

https://doi.org/10.21278/idc.2018.0445

\title{
CHARACTERISING THE AFFORDANCES AND LIMITATIONS OF COMMON PROTOTYPING TECHNIQUES TO SUPPORT THE EARLY STAGES OF PRODUCT DEVELOPMENT
}

\author{
D. Mathias, B. Hicks, C. Snider and C. Ranscombe
}

\begin{abstract}
The act of prototyping is more than the artefact produced - the process helps answer design questions. A knowledge of prototyping activities leads to better decisions in the design process. The aim of this paper is to characterise and compare prototyping techniques. A literature review explores current research into characterising prototypes, before highlighting the need for comparison. A study is reported that compares the design activity of sketching, CAD, cardboard and LEGO when used as prototypes in a group design task, showing differences in the levels of different design activities.
\end{abstract}

Keywords: prototyping, product development, early design phase, design practice

\section{Introduction}

Prototyping is a fundamental part of product development that allows the designers to test, understand and develop their ideas. Prototyping is frequently considered to be the physical embodiment of a design that allows designers to test its performance against design specifications. However, the activity of prototyping is more than just creating a tangible representation - it involves creativity and design cognition (Sanders and Stappers, 2014). As well as their use as early representations of products in development, the definition of prototypes has been expanded to reflect their value in the fuzzy front end of design (Camere and Bordegoni, 2016).

As prototypes are increasingly used more broadly in the development of new products, it is important to understand how the materials, techniques and tools used affect the outcome. The designer must choose a suitable representation for the question at hand (Houde and Hill, 1997) and so a knowledge of the relative affordances and limitations of prototyping activities can lead designers to make a better choice to support their needs at a particular stage of the design process.

The aim of this paper is to characterise and compare the affordances and limitations of current prototyping methods to see how they support product development. The paper is split into two parts: a review of existing literature on prototyping methods and their use in the design process, and an experimental study comparing how four prototyping techniques are used by groups of participants in identical circumstances. The findings of the study are then compared and contrasted with extant literature.

\section{What is a prototype?}

There does not seem to be an overarching definition of a prototype (Jensen et al., 2016) and the definitions are domain dependent, changing between architecture, software and engineering 
(Beaudouin-Lafon and Mackay, 2007). However, it is common practice to refer to a prototype as a representation of a design and prototyping as the act of using prototypes in the development of a new product. This is shown by Ulrich and Eppinger's (2012) definition of a prototype as "an approximation of the product along one or more dimensions of interest".

Prototypes can take on many roles during the product development process. Ullman (2003) defines four uses of prototypes based on their role:

- A Proof-of-Concept prototype is used to identify what approach to take in the initial stages when designing a new product.

- A Proof-of-Product prototype helps develop the physical embodiment and manufacturing viability.

- A Proof-of-Process prototype demonstrates that the chosen materials and production methods meet the product requirements.

- A Proof-of-Production prototype shows that the complete production process can achieve the required results.

However, the act of prototyping is more than just the output of a representation to be measured or evaluated - prototyping helps designers in both answering specific design questions while also giving rise to new ones (Yang, 2005). This is reflected in Camere and Bordegoni's (2016) definition of prototyping as "the activity of engaging with the product-to-be, instantiating the design process."

Menold et al. (2017), identifies three major purposes of prototyping as an activity: to encourage learning during subsystem design; to act as decision variables in the product development process; and, to enable richer discussions between designers and end users. Ulrich and Eppinger (2012) delve a little deeper, merging prototyping as an outcome and as an activity, stating that prototyping has four distinct purposes within the product development process:

- Learning - to understand the design problem and potential solutions.

- Communication - to improve communication and contribute towards a shared understanding of design intentions.

- Integration - to check components work together and to discover unexpected phenomena

- Milestones - to demonstrate that design requirements have been met

\subsection{Characterising prototypes}

Buchenau and Suri (2000) offer three classifications of prototypes: "looks like", "behaves like", and "works like". This aligns with Hallgrimsson (2012) who considers "looks like" and "works like" as classifications of prototypes. These groups roughly correspond to the level of functionality the prototype has compared to the final product. Ulrich and Eppinger (2012) add a second dimension and characterise prototypes along two major dimensions: the degree to which they are physical (as opposed to virtual) and the degree to which they implement all the attributes of the design (focussed as opposed to comprehensive).

Houde and Hill (1997) characterised prototypes into four principal categories: the role of the product being designed, its look and feel and the technical considerations required to implement the design. With integration prototypes exploring the combination of and interplay between the three other categories. Jensen et al. (2015) identified six thematic characteristics of a prototype: the material it is made from, its level of interactivity with the user, its visual detail, the purpose of the prototype, the contextual surroundings outside of the designer's control, and the technology required to produce the prototype. Alongside these dimensional descriptions of prototypes, one property they are frequently and easily characterised by is the technique employed in their creation. This term can mean the material and fabrication approach (Hallgrimsson, 2012) or the tools and methods employed (Blomkvist and Holmlid, 2011). Camere and Bordegoni (2016) state that any approach can become the medium in which a prototype is created as they argue the process of prototyping is just as important as the outcome.

These techniques include sketching and computer aided design (CAD) through to junk modelling and 3D printing as well as virtual prototyping. Given the range and importance of prototypes there exists a significant body of research concerned with the various techniques for prototyping used by designers in industry and education. For example, Yang (2009) studied concept generation and sketching and how it 
affected the design outcome. CAD and its limitations in the early stages of the design process was investigated by Lawson (2002). Ranscombe and Bissett-Johnson (2017) discuss the relationship between sketching and CAD and report a new approach to combine their benefits. In industry, Dyson extensively uses cardboard modelling in their development process to produce preliminary 3D models of their products (James Dyson Foundation, 2010). Construction kits, such as LEGO, have also been shown to be valuable tools for prototyping and designing (Garde and van der Voort, 2016; Boa et al., 2017). These different techniques can be loosely grouped into four categories: paper-based (e.g. sketching), computer/virtual-based (e.g. CAD drawings, VR prototyping), free-form physical (e.g. clay, foam and cardboard modelling), and constrained physical (e.g. construction kits, junk modelling).

Due to the broad range of prototyping purposes, approaches and techniques, several guiding frameworks have been developed to help designers make better decisions about how and when they should be prototyping. Dunlap et al. (2014) reported a heuristics-based tool they developed that guides designers in planning prototype strategies. Camburn et al. (2017) and Menold et al. (2017) expand on Dunlap et al.'s work by taking a wider view of the product development process. They have described holistic prototyping frameworks that help structure and improve prototyping throughout the design process. A crucial part of these is the characterisation of prototypes, and how the different approaches compare to each other, described in detail in the following section.

\section{Need for comparison}

Being able to choose a suitable technique at a particular stage in the product development process is critical to the success of the outcome (Camburn et al., 2015). Furthermore, Thomke (1998) states that switching between prototyping methods at the right time can have benefits of reducing cost and overall development time. In order to be able to do these there needs to be an understanding of how prototyping techniques compare with their relative affordances, limitations and suitability at different points in the design process.

The comparisons could include:

- Affordances/Limitations - what designs or behaviour does the technique encourage?

- Fidelity/Resolution - how well does the technique meet the required level of detail?

- Fit for purpose - how appropriate is the technique to answer the current design question?

- Cost/Skill/Time - how expensive or time consuming is the technique to use?

- Target Audience - how well does the technique engage with a particular audience?

On the whole, prototyping techniques have been reported or studied individually, however there are a handful of papers that compare techniques.

Häggman et al. (2015) compared sketching, CAD and foam modelling in the generation of ideas for a remote control. They found that physical prototyping (foam modelling) resulted in faster idea generation than sketching or CAD. Similarly, Isa et al. (2015) found that card modelling helped the designers produce more creative and innovative ideas when they studied sketching, card modelling and digital tools. Viswanathan and Linsey (2012) explored whether physical models induced design fixation through designers' use of sketching and wire modelling to generate functional ideas.

Another comparison of techniques was performed by Deininger et al. (2017), in the study reported the authors evaluated sketching, CAD, cardboard, 3D printed prototypes for use in gaining input from different stakeholders.

However, all these studies are only considering the outcome (e.g. ideas generated, level of stakeholder input) rather than what design behaviour the different techniques elicit and how it changes during the process of prototyping.

In the following section, a study is reported that compares four different prototyping techniques during a design task.

\section{Prototyping study}

The prototyping study aimed to supplement the literature review by providing insight into how different prototyping techniques compare to each other and their relative affordances and limitations on design activity during the product development process. Here, the hypothesis is in the existence of difference 
in process behaviour displayed by participants and initiated by the usage of different prototyping techniques, with the work aiming to inform understanding of the nature of such differences where they appear. This aim necessitates the direct comparison of multiple techniques utilised on an identical task. The study is focussed on Proof-of-Concept prototypes (described in Section 2) that are used in the early stages of the development of a new product to explore design concepts.

\subsection{Methodology}

A group design task was organised to study how four different prototyping techniques were used in the production of concept designs for a singular design brief. From the literature review it was shown that prototyping techniques could be grouped into four categories. In this study one technique from each category was chosen. The four techniques identified to investigate and compare were Sketching (from paper-based), Computer Aided Design (from computer/virtual-based), Cardboard Modelling (from freeform physical), and Construction Kits (from constrained physical). In this study the construction kit of choice was LEGO due to its familiarity and ubiquity. By selecting these methods, the spectrum of prototyping techniques is represented in the study, with the specifics of other methods or emerging systems, such as virtual reality, considered elaborations for future work.

\subsubsection{Participants}

The participants consisted of 24 Engineering Design undergraduate students (14 men and 10 women with a mean age of 19) in the first year of their course. All the students had known and similar experience in sketching, CAD and cardboard modelling through their academic courses, but none could be considered experts in any of the prototyping techniques. Controlling for LEGO was not required as the skill level in using it is very low as it was originally designed as a toy accessible to children. All students reported that they had used LEGO previously.

The participants were randomly assigned into groups of four and each group was given one of the four prototyping techniques. While characteristics such as personality and creativity impact upon the design process followed and output, studying the impact of varying prototyping techniques alone such characteristics are considered subjects for further work, and in this case, controlled solely through randomness in group member selection.

\subsubsection{Prototyping materials}

The materials provided were as follows:

- Sketching: A4 sketch pads, sketching pencils, coloured marker pens and fine-line pens.

- Cardboard: 1 and 2 ply corrugated cardboard, craft knives, hot glue guns, tape, wooden skewers and cocktail sticks.

- CAD: A computer per person, running Autodesk Inventor 3D Modelling Software.

- Construction Kits: A Classic Large Creative Brick Box consisting of 790 assorted LEGO pieces

The groups could only use the prototyping technique they were assigned and were limited to the provided materials.

\subsubsection{Design task}

The design brief was to "design a novel, disruptive approach to personal transportation for 15-20 years' time". The brief was deliberately chosen to permit a broad range of solutions that the participants could explore. Furthermore, the topic of transportation was familiar to all the participants and so it was not a prerequisite to have any engineering experience or to research the existing issues and limitations with the current approaches to understand the problem. Finally, the design brief did not favour a particular technique over another. For example, if the brief encouraged organic shapes then LEGO would be at a disadvantage due to its geometric constraints. Similarly, if the brief was for something tactile and hand held then CAD would be disadvantaged as it lacks physical interaction and a sense of scale in the designs.

After an introduction to the task, the groups had two hours to design and produce prototypes of their ideas and prepare a presentation to pitch their chosen idea. In the first 20 minutes, the groups were 
encouraged to come up with a broad range of ideas. These ideas would then be evaluated during the review phase with one concept being taken forward into the refinement phase for the rest of the session. The final 20 minutes of the allocated time was for the groups to finalise their prototypes and write a short presentation. Figure 1 shows a timeline of study, highlighting the different phases of the design task as well as the administrative sections. The timing started from the moment the groups were working on the design task.

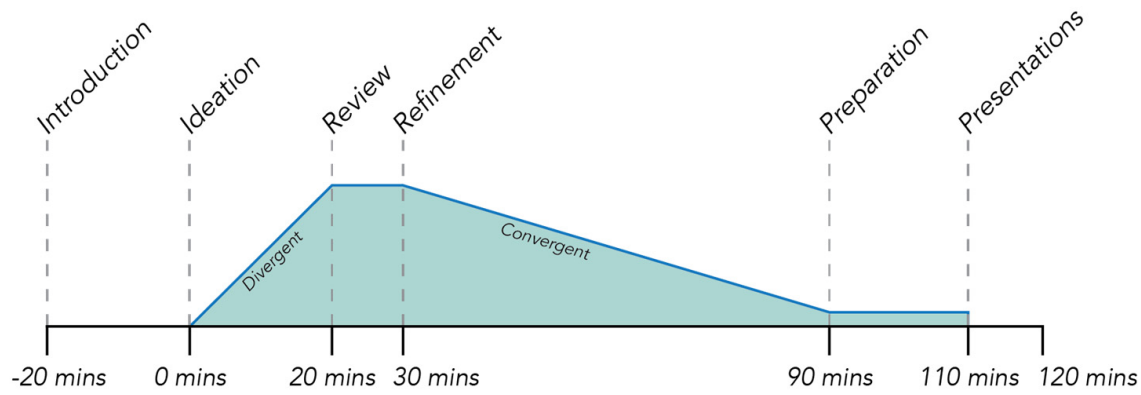

Figure 1. A timeline of the study, representing the different phases of the design task

The groups presented their designs to the others in the session and a small panel of judges. Figure 2 shows examples of some of the prototypes made by the groups during the design task.

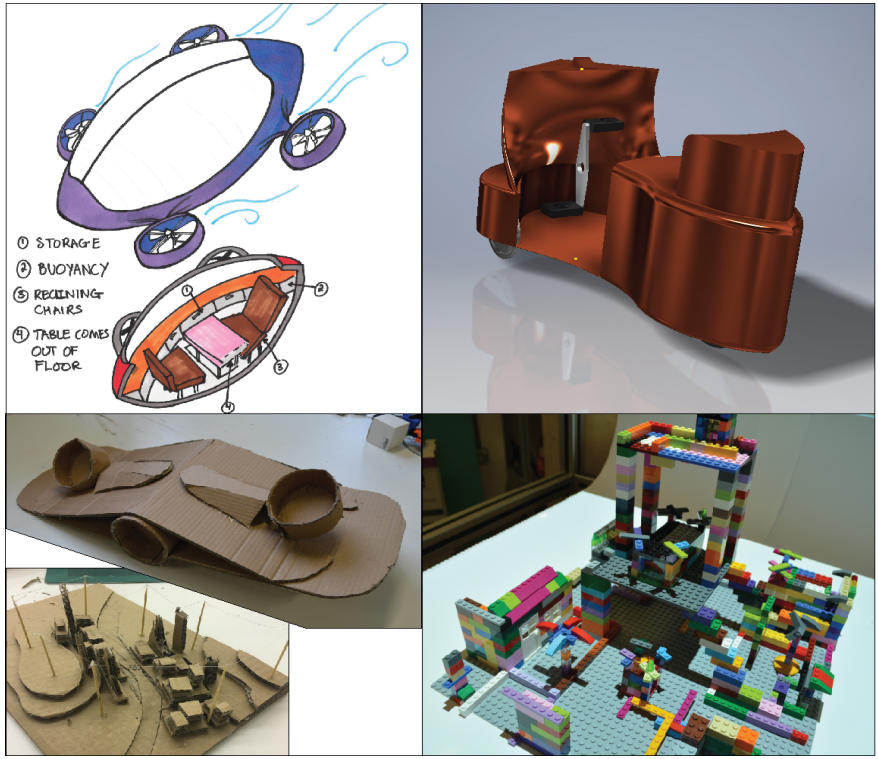

Figure 2. Examples of the prototypes produced during the design task; Clockwise from top left: Sketching, CAD, LEGO, Cardboard

\subsubsection{Data collection}

The data was collected in two ways. The primary method was through self-reporting forms that the participants had to fill in at 10 minute intervals, the secondary method was a reflective questionnaire given to the participants after the task was over.

\section{Self-reporting forms}

The self-reporting method employed in this study was a derivative on the method used by Jonson (2005) to study ideation tools. The self-reporting forms were completed every 10 minutes by the groups over the course of the design activity. An example of the self-reporting form for a single time interval can be seen in Table 1. The form covered five design activities (Problem Structuring, Ideating/Generating new 
ideas, Refining/Developing ideas, Evaluating/Critiquing Ideas, and Collaborative Work) with a catchall for any other activity performed in the 10 minute intervals.

It allowed the groups to record their engagement in the activities to three levels: None, Some, and A lot.

Table 1. Example section of the self-reporting form the groups filled in during the design task

\begin{tabular}{|r|l|l|l|}
\hline & None $(0$ mins $)$ & Some (1-3 mins) & A lot (5-10 mins) \\
\hline Problem Structuring & & & \\
\hline Ideating, Generating new ideas & & & \\
\hline Refining, Developing ideas & & & \\
\hline Evaluating, Critiquing ideas & & & \\
\hline Collaborative Work & & & \\
\hline Other (Describe) & & & \\
\hline
\end{tabular}

During the introduction to the session, the participants were briefed on how to fill in the self-reporting forms with descriptions and examples of the different design activities listed on the form. It was also explained that the activities were not mutually exclusive, allowing the participants to select 'A lot' for more than one activity if that reflected how they had spent their time.

While this approach has its limitations, it was chosen as a compromise between capturing useful data and not excessively interfering with the design task.

\section{Reflective questionnaire}

This questionnaire comprised of six questions: the first three were structured Likert scale questions, the second three were open ended questions. The questions were as follows:

1. How easy was it to use the prototyping technique to communicate the ideas in the following phases? (Ideation, Review, and Refinement).

2. How easy was it to use the prototyping technique to evaluate the following aspects of a design? (Moving Parts/Interaction, Function/Features, Scale/Relative Arrangement, Aesthetic/Form Detail, Mode of Operation/Process).

3. How easy was it to use the prototyping technique to perform the following design tasks? (Generating Ideas, Refining Ideas, Selecting the Best Idea, Developing the Chosen Idea).

These questions were all answered on a Very Difficult to Very Easy scale for each of the options. The rationale behind these questions was to capture how suitable the different prototyping techniques were for use in various phases in the design process and in representation design aspects.

The open-ended questions were as follows:

4. To what extent do you feel the prototyping technique used influenced your design?

5. How easy was it to explore changes to your design via the prototype?

6. How much did you have to explain the idea to your group members in addition to showing them your prototype?

The rationale behind the last three questions was to capture the participants' views and opinions on how they felt about using the different prototyping techniques. The information provided by the questionnaire supplemented the self-reporting forms in capturing data on the design activities that the prototyping techniques elicit. Furthermore, care was taken to ensure that all the questions were fair to the different prototyping techniques.

\subsection{Results}

The following two sections cover the results from the self-reporting forms and reflective questionnaire.

\subsubsection{Self-reporting results}

Each participant self-reported during the design task, this resulted in four sets of data per group. In order to reach a group consensus for each time interval, the responses were weighted ( 8 minutes for A Lot, 2 
minutes for Some and 0 minutes for None) and the median calculated. This was repeated for the six design activities. The results for the four techniques are plotted in Figure 3.

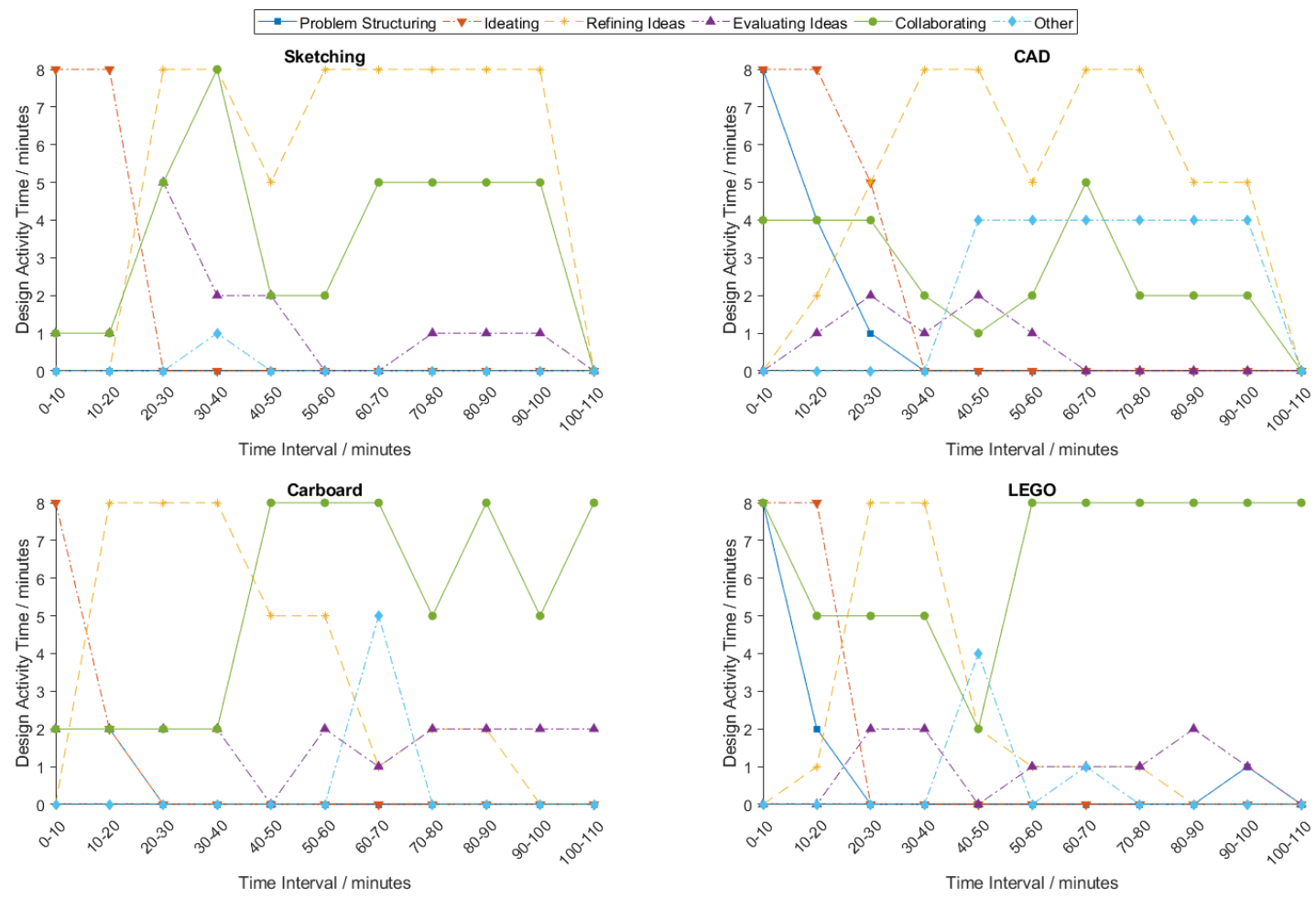

Figure 3. Graphs of the time spend in each design activity over the time intervals for the four prototyping techniques

In order to draw relative comparisons between the different techniques the absolute time values were split into the four phases of the task: ideation (0-20 minutes), review (20-30 minutes), refinement (3090 minutes) and presentation preparation (90-110 minutes). To focus on the design task, the presentation preparation phase was not included. The values were averaged across the phase and then binned into the 'None', 'Some', 'A lot' categories used in the self-reporting forms. The results are shown in Table 2.

Table 2. Time spent performing design activities in the three main phases of the design task for (a) Sketching, (b) CAD, (c) Cardboard, and (d) LEGO

\begin{tabular}{r|c|c|c} 
(a) Sketching & \multicolumn{1}{c}{ Ideation } & Review & Refinement \\
\hline Structuring & None & None & None \\
\hline Ideating & A Lot & None & None \\
\hline Refining & None & A Lot & A Lot \\
\hline Evaluating & Some & A Lot & Some \\
\hline Collaborative & Some & A Lot & Some \\
\hline Other & None & None & Some
\end{tabular}

(b) CAD Ideation Review Refinement

\begin{tabular}{r|c|c|c} 
(b) CAD & Ideation & Review & Refinement \\
\hline Structuring & A Lot & Some & None \\
\hline Ideating & A Lot & A Lot & None \\
\hline Refining & Some & A Lot & A Lot \\
\hline Evaluating & Some & Some & Some \\
\hline Collaborative & Some & Some & Some \\
\hline Other & None & None & Some
\end{tabular}

(c) Cardboard Ideation Review Refinement

\begin{tabular}{r|l|l|l}
\hline Structuring & Some & None & None \\
\hline Ideating & A Lot & None & None \\
\hline Refining & Some & A Lot & Some \\
\hline Evaluating & Some & Some & Some \\
\hline Collaborative & Some & Some & A Lot \\
\hline Other & None & None & Some \\
\hline
\end{tabular}

(d) LEGO Ideation Review Refinement

\begin{tabular}{r|c|c|c}
\hline Structuring & A Lot & None & None \\
\hline Ideating & A Lot & None & None \\
\hline Refining & Some & A Lot & Some \\
\hline Evaluating & None & Some & Some \\
\hline Collaborative & A Lot & A Lot & A Lot \\
\hline Other & None & None & Some \\
\hline
\end{tabular}




\subsubsection{Reflective questionnaire results}

To get a group consensus in the Likert scale questions, the median of the groups' responses was taken. The results for the first three questions can be seen in Table 3 .

Table 3. The results of questions 1-3 of the reflective questionnaire; Answer scale: 2 (Very easy), 0 (Neutral), -2 (Very difficult)

\begin{tabular}{|c|c|c|c|c|c|}
\hline \multirow{4}{*}{$\begin{array}{l}\text { 1: How easy was it to use the } \\
\text { prototyping technique to } \\
\text { communicate the ideas in the } \\
\text { following phases? }\end{array}$} & \multirow{4}{*}{$\begin{array}{r}\text { Ideation } \\
\text { Review } \\
\text { Refinement }\end{array}$} & Sketching & CAD & Cardboard & LEGO \\
\hline & & 2 & -0.5 & -1 & -1.5 \\
\hline & & 2 & 0 & -1 & 1 \\
\hline & & 1 & 0 & 1 & -0.5 \\
\hline \multirow{5}{*}{$\begin{array}{l}\text { 2: How easy was it to use the } \\
\text { prototyping technique to } \\
\text { evaluate the following } \\
\text { aspects of a design? }\end{array}$} & \multirow{5}{*}{$\begin{array}{r}\text { Moving Parts } \\
\text { Function/features } \\
\text { Scale/Arrangement } \\
\text { Aesthetics } \\
\text { Mode of Operation }\end{array}$} & -1 & 0.5 & -1 & -1 \\
\hline & & 0 & 0 & 0 & 0 \\
\hline & & 1 & 1 & 1 & -1 \\
\hline & & 1.5 & 1 & -1 & -1 \\
\hline & & 0 & 0 & 0 & 0 \\
\hline \multirow{4}{*}{$\begin{array}{l}\text { 3: How easy was it to use the } \\
\text { prototyping technique to } \\
\text { perform the following design } \\
\text { tasks? }\end{array}$} & \multirow{4}{*}{$\begin{array}{r}\text { Ideation } \\
\text { Refining ideas } \\
\text { Selection } \\
\text { Development }\end{array}$} & 1.5 & -1.5 & -2 & -0.5 \\
\hline & & 1 & -1 & 0 & 0 \\
\hline & & 1 & -1 & -1 & 0 \\
\hline & & 1 & 0.5 & 1 & 1 \\
\hline
\end{tabular}

The answers to the open-ended questions were analysed using a coding scheme. In question 4 the answers were coded based on whether the technique 'limited' their designs or 'facilitated' them. Question 5 was coded for sentiment of 'easy' or 'difficult'. The LEGO and Cardboard groups showed some disagreement amongst themselves. Responses to question 6 were coded using a scale based on the level of explanation required: 'none', 'some explanation', and 'substantial explanation'. The coded responses are summarised in Table 4.

Table 4. Coded responses to the open-ended questions (4-6) of the reflective questionnaire

\begin{tabular}{|c|c|c|c|c|}
\hline & Sketching & CAD & Cardboard & LEGO \\
\hline $\begin{array}{l}\text { 4: To what extent do you feel the } \\
\text { prototyping technique used influenced } \\
\text { your design? }\end{array}$ & Facilitated & Limited & Limited & Limited \\
\hline $\begin{array}{l}\text { 5: How easy was it to explore changes } \\
\text { to your design via the prototype? }\end{array}$ & Easy & Difficult & $\begin{array}{c}\text { Easy (some } \\
\text { disagreement) }\end{array}$ & $\begin{array}{c}\text { Easy (some } \\
\text { disagreement) }\end{array}$ \\
\hline $\begin{array}{l}\text { 6: How much did you have to explain } \\
\text { the idea to your group members in } \\
\text { addition to showing them your } \\
\text { prototype? }\end{array}$ & Some & Substantial & Some & Substantial \\
\hline
\end{tabular}

\subsection{Discussion}

This section discusses the results from the self-reporting forms and the reflective questionnaires, as well as the limitations of the methodology and potential scope for further work.

\subsubsection{Results}

From the self-reporting forms (see Table 2), it was interesting to note that sketching group spent no time structuring the problem and dived straight into generating ideas. While the LEGO and CAD groups discussed the task within their groups and only started using their prototyping technique once they were happy to proceed. It is contended that this behaviour arises largely because the groups were strictly 
limited to their prototyping technique - so only the sketching group could augment their early ideation discussions with quick, light-weight, low effort sketches, while LEGO and CAD required a more methodical, hierarchical approach to representing their designs. This was also shown in the responses to questions 1 and 3 in the reflective questionnaire (see Table 3), where sketching was considered to be easy to use in Ideation, but cardboard, LEGO, and CAD were considered to be difficult to very difficult. Despite the differences in structuring the problem, all the groups reported high levels of ideation activity at the start that dropped off as the task progressed. This was expected as the groups were encouraged to think divergently during the Ideation phase but then to choose and refine an idea in the Review and Refinement phases. A caveat to the reported results is the fact that self-reporting does not capture how the group were using their prototyping technique but rather whether they had been performing a design activity.

The sketching and CAD groups spent more time refining their chosen ideas than the cardboard and LEGO groups. As the cardboard and LEGO groups were aware of the limitations in fidelity of their prototyping techniques (A LEGO group said, "we wanted to create something that could be effectively presented with LEGO") they did not strive for high levels of aesthetic detail but rather prototypes that were sufficient to explain their concepts. Conversely the sketching and CAD groups were using higher fidelity techniques (The sketching group commented that sketching "gave [them] a lot of freedom in complexity of design and detail") and so they reported spending more time producing prototypes with higher levels of detail - potentially for aesthetic gain rather than meaningful design improvements. This was supported by the responses to the reflective questionnaire (see Table 4, Question 4), did the prototyping technique influence the design. The cardboard and LEGO groups stated that their "technique limited their designs", while the sketching group stated "it facilitated them". Despite the higher fidelity, the CAD group stated that using CAD software was potentially limiting on their design freedom as "complex shapes were difficult to create".

The concept of sunk cost in design tools was explored by Viswanathan and Linsey (2011) and is relevant in explaining the attitudes of the groups to the time and perceived effort of making changes. When asked how easy it was to explore changes with their prototyping technique (reflective question 5) most groups referred to the time to create their designs or their lack of ability in the technique. The sketching group said changes were easy as they could quickly "draw over" designs, while the CAD group said changes were difficult and time consuming, and that it "was often easier to totally rebuild than to adjust" designs. On the whole the cardboard and LEGO groups thought that making changes were easy, however there was some disagreement within the groups. This disagreement stems from the apparent size of changes with small adaptations being achievable but large changes considered too difficult or time consuming to perform. While the groups using LEGO viewed its orthogonality as a limitation, the reconfigurable nature of brick interfaces helps lower the effort required in making changes and encourages reconstruction and reuse of parts - an affordance not present in the other prototyping techniques.

There was little difference in the levels of evaluating reported by the groups with all the groups reporting some evaluating throughout the design task. However, there was one notable exception, the LEGO groups reported that they did no evaluating during the ideation phase.

As the design task was group based, it was unsurprising to see that each prototyping technique had at least some collaborative activity over the entire session. However, the groups using physical techniques (LEGO and cardboard) reported more collaboration amongst themselves, particularly in the refinement phase. This emphasis on collaboration comes from the fact that the LEGO and cardboard groups had a physical object that they could interact with and discuss effectively becoming an intermediary object (Boujut and Blanco, 2003). In their reflections, the groups using LEGO and Cardboard stated that on the whole communicating ideas with their technique was difficult and that they required supplementary discussion and in some cases substantial explanation. Consequently, the lack of fidelity and increased ambiguity in the physical techniques actively encouraged more collaborative dialogue.

As stated in the introduction, the act of prototyping is more than the outcome of a physical artefact but the activity itself informs designers and elucidates the design problem. Some of the groups focussed on producing a realistic, high fidelity prototype rather than developing the conceptual details of their ideas. As a result, some of the groups became fixated and were reluctant to iterate and change their designs. The ability to design-build-test is valuable when prototyping and so important characteristics of 
prototyping techniques are quick ideation, simple construction and redesign, and encouragement of collaboration when designing. Therefore, it is contended that a combination of techniques would be more suitable for prototyping in the early stages of the design process as complementary affordances could be matched and limitations reduced. From the findings, a strategy that combined sketching and LEGO would provide the benefits of disposable, light-weight ideation and annotation with the tangibility and editability of a physical prototype with the increase in collaborative work. This is congruent with the findings from Viswanathan and Linsey (2012) and Faas et al. (2014).

\subsubsection{Methodology}

In order to record the design activity the participants were undertaking during the design task, a compromise had to be made between recording accurate data and limiting interference in the study. Video recording and the subsequent transcribing and analysis would have been far too time consuming and expensive with little guarantee of more accurate data. The self-reporting forms, filled at 10 minute intervals, were an acceptable solution for this foundational study. However, their biggest limitation is that they rely on the participants to accurately report their own design activity into discretised categories and time intervals - something that is challenging when the nature of the activities is often fluid and frequently changing between them. This limitation was mitigated by taking the median result of the participants using each prototyping technique to arrive at a group consensus.

The data collection was supplemented with the reflective questionnaire which helped verify some of the findings from the self-reporting forms. It also gave the participants a chance to provide further insight into their feelings about the prototyping techniques that could not be recorded in the self-reporting forms. The mix of structured Likert scale and open-ended questions allowed the participants to provide useful data as well as some of their longer thoughts on the prototyping techniques. However, there was some discrepancy between the self-reporting forms and the reflective questionnaire highlighting the need for a more quantitative way of capturing data. Furthermore, the questions posed require some improvement as the use of "How easy was it to do X?" is highly subjective and does not necessarily produce consistent results between participants.

\subsubsection{Further work}

This study was performed with six groups of four participants and so generalising the results was not possible. However, the results have shown demonstrable differences in design activity between the four prototyping techniques and their affordances and limitations in early design stages. As this is the first comparison of design activity between prototyping techniques more research into the individual techniques is needed to allow for more in-depth conclusions to be drawn. The area of further work would include two streams: one to study each technique and its affordances in more detail, and a second to explore the affect of combining two different prototyping techniques on the design process.

\section{Conclusion}

The aim of this paper was to characterise and compare the affordances and limitations of common prototyping techniques in the early stages of the product development process. The first half of the paper performed a review of existing research with the definition of prototyping explored, followed by how other authors in the field characterise prototyping, emphasising that it is not just the outcome but the process that aids the designer. Previous prototyping comparison studies were referenced and the need for a comparison between prototyping techniques was posited as a way of being able to affect and manage the use of prototypes in the design process. The second half of the paper described a study undertaken to understand how the design activity of sketching, CAD, cardboard modelling and LEGO construction compare when used as prototyping techniques in a group design task. In all cases, ideation activity started high and then quickly dropped off. The sketching group did not spend any time structuring the design problem, while the LEGO and CAD groups spent a lot of time planning their approaches in the ideation phase. The physical techniques (LEGO and cardboard) encouraged more collaborative work throughout the entire task but the participants felt the techniques limited their design freedom. The higher fidelity techniques (sketching and CAD) resulted in the groups spending more time refining the detail and aesthetics of their ideas in the later stages. Furthermore, the differences in the 
groups' attitude towards changing designs was explored and related to sunk cost. However, further research is required before more conclusive statements about each prototyping technique's suitability in different stages of the design process can be made. However, from the findings it is apparent that a combination of sketching and LEGO would merge the affordances and reduce the limitations of each.

\section{References}

Beaudouin-Lafon, M. and Mackay, W.E. (2007), "Prototyping Tools and Techniques”, In: Jacko, J.A. (Ed.), The Human-Computer Interaction Handbook: Fundamentals, Evolving Technologies and Emerging Applications, 2nd ed., CRC Press, Florida, USA.

Blomkvist, J. and Holmlid, S. (2011), "Existing Prototyping Perspectives: Considerations for Service Design”, Nordic Design Research Conference, pp. 1-10.

Boa, D., Mathias, D. and Hicks, B. (2017), "Evolving LEGO: prototyping requirements for a customizable construction kit", ICED 2017: International Conference on Engineering Design, August 21 - 25, 2017, pp. 297-306.

Boujut, J.-F. and Blanco, E. (2003), "Intermediary Objects as a mean to foster Co-operation”, Engineering Design Computer Supported Cooperative Work, Vol. 12 No. 2, pp. 205-219.

Buchenau, M. and Suri, J.F. (2000), "Experience Prototyping", Conference on Designing interactive systems: processes, practices, methods, and techniques, pp. 424-433. http://doi.acm.org/10.1145/347642.347802

Camburn, B., Viswanathan, V., Linsey, J., Anderson, D., Jensen, D. et al. (2017), "Design prototyping methods: state of the art in strategies, techniques, and guidelines", Design Science, Vol. 3, p. e13. https://doi.org/10.1017/dsj.2017.10

Camburn, B.A., Jensen, D., Crawford, R., Otto, K. and Wood, K. (2015), "Evaluation of a Strategic Method To Improve Prototype Performance With Reduced Cost and Fabrication Time", Proceedings of the 20th International Conference on Engineering Design, July 27 - 30, 2015, pp. 1-10.

Camere, S. and Bordegoni, M. (2016), "A lens on future products: An expanded notion of prototyping practice", Proceedings of International Design Conference, DESIGN, DS 84, pp. 155-164.

Deininger, M., Daly, S., Sienko, K., Lee, J., Obed, S. and Effah Kaufmann, E. (2017), "Does Prototype Format Influence Stakeholder Design Input?", Proceedings of the 21st International Conference on Engineering Design (ICED17), August 21 - 25, 2017, pp. 553-562.

Dunlap, B.U., Hamon, C.L., Camburn, B.A., Crawford, R.H., Green, M.G. and Wood, K.L. (2014), "HueristicsBased Prototyping Strategy Formation - Development and Testing of a New Prototype Planning Tool", International Mechanical Engineering Congress \& Exposition IMECE2014. https://doi.org/10.1115/IMECE2014-39959

Faas, D., Bao, Q. and Yang, M.C. (2014), "Preliminary Sketching and Prototyping: Comparisions in Exploratory Design-and-build Activities", ASME 2014 International Design Engineering Technical Conferences and Computers and Information in Engineering Conference, Vol. 7: 2nd Biennial International Conference on Dynamics for Design; 26th International Conference on Design Theory and Methodology, Buffalo, New York, USA, August 17-20, 2014, pp. 1-9. https://doi.org/10.1115/DETC2014-34928

Garde, J.A. and van der Voort, M.C. (2016), "Could LEGO ${ }^{\circledR}$ Serious Play ${ }^{\circledR}$ be a useful technique for product co-design?”, Proceedings of DRS 2016, Design Research Society 50th Anniversary Conference, pp. 1-19.

Häggman, A., Tsai, G., Elsen, C., Honda, T. and Yang, M.C. (2015), "Connections Between the Design Tool, Design Attributes, and User Preferences in Early Stage Design”, Journal of Mechanical Design, Vol. 137 No. 7, pp. 71101. https://doi.org/10.1115/1.4030181

Hallgrimsson, B. (2012), Prototyping and Modelmaking for Product Design, Laurence King Publishing, London.

Houde, S. and Hill, C. (1997), “What do prototypes prototype?”, In: Helander, M.G., Landauer, T.K. and Prabhu, P.V. (Eds.), Handbook of Human Computer Interaction, pp. 367-381.

Isa, S.S., Liem, A. and Steinert, M. (2015), "The Value of Prototypes in the Early Design and Development Process", 20th International Conference on Engineering Design (ICED 15), July 27 - 30, 2015, pp. 1-8.

James Dyson Foundation (2010), Engineering Box - Teacher's Pack. [online] James Dyson Foundation. Available at: http://www.jamesdysonfoundation.co.uk/resources/engineering-box-teachers-pack/

Jensen, L.S., Özkil, A.G. and Mortensen, N.H. (2016), "Prototypes in engineering design: definitions and strategies", International Design Conference - Design 2016, pp. 821-830.

Jensen, M., Balters, S. and Steinert, M. (2015), "Measuring Prototypes - a standardized quantitative description of prototypes and their outcome for data collection and analysis", Proceedings of the 20th International Conference on Engineering Design (ICED15), Vol. 2 No. 1, pp. 1-14.

Jonson, B. (2005), "Design ideation: The conceptual sketch in the digital age", Design Studies, Vol. 26 No. 6, pp. 613-624. https://doi.org/10.1016/j.destud.2005.03.001 
Lawson, B. (2002), “CAD and Creativity: Does the Computer Really Help?”, Leonardo, Vol. 35 No. 3, pp. 327331.

Menold, J., Jablokow, K.W. and Simpson, T.W. (2017), "Prototype for X (PFX): A holistic framework for structuring prototyping methods to support engineering design", Design Studies, Vol. 50, pp. 70-112. http://dx.doi.org/10.1016/j.destud.2017.03.001

Ranscombe, C. and Bissett-Johnson, K. (2017), "Digital Sketch Modelling: Integrating digital sketching as a transition between sketching and CAD in Industrial Design Education”, Design and Technology Education, Vol. 22 No. 1, pp. 1-15.

Sanders, E.B.N. and Stappers, P.J. (2014), "Probes, toolkits and prototypes: Three approaches to making in codesigning", CoDesign, Vol. 10, No. 1, pp. 5-14. https://doi.org/10.1080/15710882.2014.888183

Thomke, S.H. (1998), "Managing Experimentation in the Design of New Products", Management Science, Vol. 44 No. 6, pp. 743-762. https://doi.org/10.1287/mnsc.44.6.743

Ullman, D.G. (2003), The Mechanical Design Process, 3rd ed., McGraw-Hill, New York.

Ulrich, K.T. and Eppinger, S.D. (2012), Product Design and Development, 5th ed., McGraw-Hill, New York.

Viswanathan, V.K. and Linsey, J. (2011), "Design Fixation in Physical Modeling: An Investigation on the Role of Sunk Cost”, ASME 2011 International Design Engineering Technical Conferences \& Computers and Infomation in Engineering Conference, pp. 119-130. https://doi.org/10.1115/DETC2011-47862

Viswanathan, V.K. and Linsey, J.S. (2012), "Physical Models and Design Thinking: A Study of Functionality, Novelty and Variety of Ideas", Journal of Mechanical Design, Vol. 134 No. 9, pp. 91004. https://doi.org/10.1115/1.4007148

Yang, M.C. (2005), “A study of prototypes, design activity, and design outcome”, Design Studies, Vol. 26 No. 6 , pp. 649-669. https://doi.org/10.1016/j.destud.2005.04.005

Yang, M.C. (2009), "Observations on concept generation and sketching in engineering design", Research in Engineering Design, Vol. 20 No. 1, pp. 1-11. https://doi.org/10.1007/s00163-008-0055-0

David Mathias, Research Engineer

University of Bristol, Mechanical Engineering

Flat 3, BS82EJ Bristol, United Kingdom

Email: david.mathias@bristol.ac.uk 